\title{
Optimal pricing and complex analysis with carbon emission reduction preference in an apparel supply chain
}

\author{
Junhai Ma · Zongxian Wang
}

Received: date / Accepted: date

\begin{abstract}
In this paper, we study the supply chain competition models that consider consumers' low-carbon consumption preferences. By constructing the supply chain of manufacturers and retailers with different market positions, two game types, decentralized decision making and centralized decision making are proposed, and the static and dynamic game methods are combined respectively for research. Although research has found that centralized decision making is always better than decentralized decision making under the static game mode, when considering the long-term dynamic evolutionary game, the average profit of decentralized decision making may be better than the average profit of centralized decision making. Moreover, there are complex dynamic characteristics under dynamic games. In order to fully understand the nature of the dynamic game systems, we discussed the stability, local bifurcation, and global bifurcation of these dynamic systems. It is found that although dynamic game systems may lose stability with changes in parameters, they are better than static game results in some cases, this is benefi-
\end{abstract}

Junhai Ma, Zongxian Wang

College of Management and Economics, Tianjin University, Tianjin, People's Republic of China

E-mail: mjhtju@aliyun.com,zongxianw201709@126.com cial to decision-makers and has practical management significance.

Keywords Optimal pricing · Carbon emission reduction · Dynamic game $\cdot$ Stability

\section{Mathematics Subject Classification (2020) 65P20 - 91A 80}

\section{Introduction}

Facing severe environmental problems, countries around the world have successively proposed carbon emission reduction plans and policies. Although China is a developing country, it is at the forefront of the world in facing sustainable development issues. In 2020, it has proposed to reach the peak of carbon emissions by 2030 , and strive to achieve carbon neutrality by 2060 .

As a major manufacturing country, China will have to make great efforts in order to achieve its carbon neutrality goal. According to the data of the United Nations Environment Programme, more than $10 \%$ of global carbon emissions by the fashion industry, and textile dyeing becomes the world's second-largest polluter[31, 33],

Consider low-carbon strategies in the aparel manufacturing process, which is the trend 
of social and economic development. Green economy, green life, and green consumption are the only way for human development in the future. With the development of human society, the massive consumption of non-renewable resources, and the continuous deterioration of the natural environment, we must incorporate sustainable development strategies into industrial development, and the entire product life cycle must be green and low-carbon.

Now many clothing manufacturers have begun to pay attention to the issue of carbon emission reduction and actively introduce green and low-carbon technologies to give clothing new connotation and quality. Shenzhou International is one of the world's largest apparel manufacturers, and it has become the largest supplier of apparel in NIKE, ADIDAS, PUMA, and Uniqlo, and it invests a lot of money in fabric research and development every year.

Such large-scale apparel manufacturers often have their own products and brands, and in addition to supplying retailers, they also sell themselves. This is similar to other well-known industries, such as the retail and direct sales of Gree, and the retail and direct sales of Huawei equipment.

In this paper, we will combine consumers' low-carbon preference for products to study the game of a supply chain composed of a manufacturer and a retailer. We considered the situation when the manufacturer is dominant and the cooperation between the manufacturer and the retailer, and combined the static game theory and the long-period dynamic game theory to analyze and discuss the optimal pricing decisions under different structures.

This paper is organized as follows. Section 2 provides a review of green and low-carbon literature in the apparel industry and other similar industries. Section 3 presents the models structures, and in Section 4 we analysis the static and dynamic decentralized models. Section 5 develops the centralized models and analyzes the complex dynamics. We compare the profit relationships under different game struc- tures in Section 6, and finally conclude in Section 7 .

\section{Literature review}

This paper studies the pricing issues in the apparel supply chain that considers consumers' low-carbon consumption preferences. Two game models with different market structures are constructed, and the static game and dynamic game methods are combined respectively for discussion. Our study is motivated by two streams of literature. The first stream is the studies on the pricing in a framework of static game for a apparel supply chain. The second stream is related to the stability and chaotic behavior in the dynamic game of a multi-channel supply chain, particularly the dynamic pricing process.

Nowadays, consumers are paying more and more attention to the sustainability of clothing, so clothing companies have to put sustainable development in a more important position $[8,13]$. Kumar and Yadav [18] investigate the impact of shopping motivation on consumers' intention to buy green apparel, this will helps managers and operators to promote sustainable development through green apparel. Moreover, Gardas et al. [15] pointed out that both negative impact on the environment and society and low level of integration will have a major impact on the sustainable development of apparel and textile industries. In order to achieve the sustainable development goals, Cai and Choi [9] studied the conditions of the textile and apparel supply chain in the sustainable development process.

The garment industry has played an important role in China's external development and has become the world's largest garment producer and exporter, contributing a large amount of GDP to the development of the national economy. As consumers' demand for green products increases, there are more and more relevant researches.

Due to consumers' preference for low-carbon products and green products that are envi- 
ronmentally friendly, governments and enterprises will tend to produce low-carbon products. Zhang et al. [37] discussed the game relationship between the government and the manufacturer when manufacturers adopt the two strategies of green technology and purchasing carbon credits, and analyzed the different powers by constructing a supply chain model under three power structures. Zhu and He [40] investigated the green product design issues in supply chains under competition, which modeled the process of product development decisions, especially the decision on the greenness level of the product.

The development of the green apparel industry requires investment in related technology, and how to share the investment cost is also a key research direction. Adhikari and Bisi [1] studied a collaboration mechanism that considers greening cost sharing contract and profit sharing contract in a green apparel supply chain. Cai et al. [10] study the mechanism for profit coordination with a fashion retail supply chain.

Further, the research on the apparel industry chain is not limited to this, for example Plotkina and Saurel [30] studied the impact of virtual try-on technology on consumers. Guo et al. [16] develop a fashion supply chain that considers consumer returns to affect green product development. Pal and Yasar [28] presents a blockchain-based architecture for the IoT applications, which brings distributed data management to support transactions services within a multi-party apparel business supply chain network.

There is also related empirical research work on the improvement of the profits of members in the apparel industry chain and energysaving $[26,29,27]$, and these empirical studies corroborate related theoretical studies.

Another research content of this paper is to study the dynamic game of supply chain in combination with complex system theory. Early research on complex systems paid more attention to theoretical research [12], but with the development of the theory, more and more scholars combined this theory with other sub- ject models and achieved good results $[3,14$, $32]$.

In the research work on the theory of dynamic oligopoly game, most scholars study the complex characteristics of the dynamic system by constructing a dynamic game model. In the process of constructing a dynamic game model, we can start from different game types, such as combining the Cournot game model for research. Zhou et al. [39] constructed a dynamic two-stage Cournot duopoly game model with a research and development effect and product differentiation. Cao et al. [11] established a dynamic duopoly Cournot game model with bounded rationality and consumer surplus based on oligopoly game theory. Wang et al. [34] discussed the complex dynamic behaviors of enterprises in the process of advertising competition, in which a two-stage dynamic Cournot model was constructed.

In addition, it can also be combined with Stackerlberg game model for research. For example, Xiao et al. [35] studied a duopoly Stackelberg game model. Companies participating in the game have heterogeneous products. As companies make decisions in order, the system will Shows complex dynamic properties. Yang et al. [36] studied the Stackelberg game model of duopoly with bounded rationality strategy, and discussed the dynamic properties of the system under different parameters, and found that there is chaos phenomenon. Askar [4] studied the Stackelberg game model consisting of three competing companies, and Askar [5] studied the Stackelberg game of duopoly under the assumption of differentiated products.

Combining complex dynamics to study longperiod dynamic games is a very valuable thing [6]. By combining the theory, the complex characteristics existing in the system can be discovered, and effective decision making options can be provided for decision-makers $[23,24,17,19]$. In our paper, we not only discussed the local stability of equilibrium points, but also found the coexistence attractor from the complex dynamics. The basin of attraction is simulated through numerical simulation [2]. Through the 
description of the two-dimensional and threedimensional basin of attraction, the selection range of the initial value is provided for decisionmakers more clearly, which can effectively avoid divergence.

Similar research work includes [38] studied a two-stage oligopoly game model with collusion behavior. Bao et al. [7] combined with the electric vehicle industry, the short-term and long-term repeated game behaviors of two parallel supply chains are studied. Ma et al. [22] studied the dynamic game problem in the multichannel supply chain, and discussed the stability of the system and the basin of attraction. Mai et al. [25] develops a dynamic pricing game model based on a long-term gradient adjustment mechanism for a book supply chain that consists of a publisher and an e-tailer. [21] studied the showrooming in dual-channel retail, and made a dynamic analysis of online and offline sales models. Ma et al. [20] studied optimal decisions of dual-channel game model considering the inputs of retailing service.

Different from the existing literature, the main contributions of this paper include the following aspects:

1. Considering consumers' low-carbon consumption preferences in the apparel supply chain;

2. Compares the profits of static games and dynamic games;

3. Studied the three-dimensional basin of attraction of the complex dynamic game models;

4. Analyzes the coexistence attractor phenomenon in the dynamic game model.

\section{The models}

\subsection{Model description and parameter definition}

In this paper, in order to be able to adapt to consumer needs, manufacturers will introduce carbon emission reduction technologies in the production process to improve the environmental friendliness of products and the low- carbon products. There are two kinds of decision making models. The first is that manufacturers act as leaders and invest in carbon reduction, while retailers act as followers, shown in Fig. 1(a). The second situation is the joint decision making of manufacturers and retailers, shown in Fig. 1(b).

In the first case, the manufacturer needs to consider the carbon emission reduction level $e$, the wholesale price $w$ and the direct selling price $p_{m}$, and the retailer needs to determine the retail price $p_{r}$. In the second case, the manufacturer and retailer jointly decide on low-carbon levels, direct selling price $p_{m}$, and the retail price $p_{r}$.

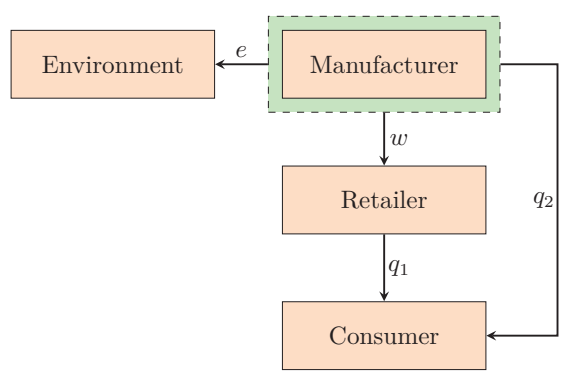

(a) Decentralized model

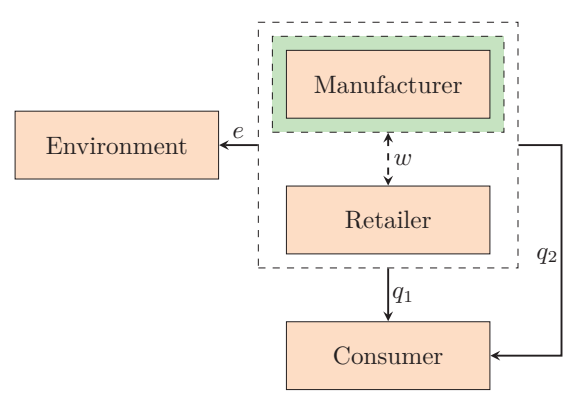

(b) Centralized model

Fig. 1 Model decision sequence.

For clarity, we will summarize the parameters and decision variables in Table 1 .

\section{Decentralized model}

In order to better fit the actual situation, we first give a decentralized decision making model. 
Table 1 Description of parameters and variables.

\begin{tabular}{ll}
\hline Symbols & Description \\
\hline \multicolumn{2}{l}{ Model parameters } \\
\hline$a$ & Potential market size. \\
$b$ & Price sensitivity. \\
$c$ & Unit production cost. \\
$\gamma$ & Consumers' sensitivity of carbon emission. \\
$\rho$ & Carbon emission reduction investment coefficient. \\
$\theta$ & Market share of manufacturer channel. \\
$1-\theta$ & Market share of retailer channel. \\
\hline Decision variables \\
\hline$p_{r}$ & Price of the retailer. \\
$p_{m}$ & Price of the manufacturer. \\
$w$ & Wholesale price of unit product. \\
$e$ & Carbon emission reduction level. \\
\hline Other variables \\
\hline$\pi_{r}$ & Profits of the retailer. \\
$\pi_{m}$ & Profits of the manufacturer. \\
$\pi_{T}$ & Total profits of the manufacturer and retailer. \\
\hline
\end{tabular}

In general, when manufacturers have more market power, in order to be able to compete with other oligarchs in the market, they will often update their products and incorporate new technologies to increase its competitive advantage in the market, thereby further expanding the market size.

In the process of a single-period game, since all participants have an understanding of the current market information, they generally adopt a rational decision making method. Manufacturers have a large market power, so they can be regarded as leaders in the Stackerlber game, while retailers are followers. Therefore, the decision sequence in the supply chain model is that the manufacturer first decides the direct selling price $p_{m}$, the wholesale price $w$, and the product's carbon emission reduction level $e$, and then the retailer decides its own retail price $p_{r}$.

The demand functions as follows,

$q_{m}=\theta a-p_{m}+b p_{r}+\gamma e$

$q_{r}=(1-\theta) a-p_{r}+b p_{m}+\gamma e$

where $q_{m}, q_{r}$ represent the quantity of manufacturer and retailer, $p_{m}, p_{r}$ represent the cor- responding sales price respectively, $b$ is the consumer's sensitivity coefficient to price, and $\gamma$ is the consumer's preference coefficient for lowcarbon products. Since we normalize the coefficient of self price in the demand function, we need to meet the constraint condition $0<b<$ $1,0<\gamma<1$.

According to the above assumptions, the profit functions of the manufacturer and retailer are

$$
\begin{aligned}
& \pi_{m}=(w-c) q_{r}+p_{m} q_{m}-\frac{1}{2} \rho e^{2} \\
& \pi_{r}=\left(p_{r}-w\right) q_{r}
\end{aligned}
$$

Both players of the game will aim to maximize their own profits, but because of different market power, their decision making sequence is also different. As described above, when the manufacturer has a dominant position, the manufacturer is the leader and the retailer is the follower. By backward induction method, we first derive the retailer's response function to the manufacturer, from the firstorder condition of $\frac{\partial \pi_{r}\left(p_{r}\right)}{\partial p_{r}}=0$, we can obtain

$p_{r}^{*}\left(p_{m}, w, e\right)=\frac{1}{2}\left(a+b p_{m}+w+e \gamma-a \theta\right)$ 
$\pi_{m}\left(p_{m}^{*}, w^{*}, e^{*}\right)=(w-c)\left(\theta a-p_{m}+b p_{r}^{*}+\gamma e\right)+p_{m}\left((1-\theta) a-p_{r}^{*}+b p_{m}+\gamma e\right)-\frac{1}{2} \rho e^{2}$

Thereby the optimal wholesale price, direct selling price, carbon emission reduction level and retail price as follows.

$$
\begin{aligned}
& p_{m}^{*}=\frac{(1+b) c \gamma^{2}+a\left(\gamma^{2}(-1+2 \theta)+4 b(-1+\theta) \rho-4 \theta \rho\right)}{2(1+b)\left((3+b) \gamma^{2}+4(-1+b) \rho\right)}, \\
& w^{*}=\frac{(1+b) c\left((4+b) \gamma^{2}+4(-1+b) \rho\right)+a\left(-\left((2+b) \gamma^{2}(-1+2 \theta)\right)-4(1+(-1+b) \theta) \rho\right)}{2(1+b)\left((3+b) \gamma^{2}+4(-1+b) \rho\right)} \\
& e^{*}=-\frac{\gamma((-1+b) c+a(1+b+\theta-b \theta))}{(3+b) \gamma^{2}+4(-1+b) \rho} \\
& p_{r}^{*}=\frac{-a(3+2 b) \gamma^{2}(-1+2 \theta)+2 a\left(-3+b^{2}-(-1+b)(3+b) \theta\right) \rho+(1+b) c\left(3 \gamma^{2}+2(-1+b) \rho\right)}{2(1+b)\left((3+b) \gamma^{2}+4(-1+b) \rho\right)}
\end{aligned}
$$

Proposition 1 When $\rho>\frac{-3 \gamma^{2}-b \gamma^{2}}{-4+4 b}$, we can obtain the optimal $p_{r}^{*}, p_{m}^{*}, w^{*}, e^{*}$.

Proof First, we have $\frac{\partial \pi_{r}}{\partial p_{r}}=a+b p_{m}-2 p_{r}+$ $w+e \gamma-a \theta$ and $\frac{\partial^{2} \pi_{r}}{\partial^{2} p_{r}}=-2<0$.

Then if we can obtain the optimal decisions, Hesse matrix $H=\left(\begin{array}{ccc}-2+b^{2} & b & \frac{(2+b) \gamma}{2} \\ b & -1 & \frac{\gamma}{2} \\ \frac{(2+b) \gamma}{2} & \frac{\gamma}{2} & -\rho\end{array}\right)$ should be negative definite. And due to $0<$ $b<1,0<\gamma<1$, we can have $-2+b^{2}<0$ and $\left|\begin{array}{cc}-2+b^{2} & b \\ b & -1\end{array}\right|=2-2 b^{2}>0$. Therefore, let $\operatorname{det}(H)=\frac{1}{2}(1+b)\left((3+b) \gamma^{2}+4(-1+b) \rho\right)<$ 0 , it can be derived that $\rho>\frac{-3 \gamma^{2}-b \gamma^{2}}{-4+4 b}$.

\subsection{Dynamic decentralized model}

In the static game process, we considered the optimal pricing problem from the perspective that the participants are all rational decision makers, but as the product is updated, the company will adjust the future price based on the optimal pricing strategy at this time. This is the extension of the static game in this sec- tion, the repetitive dynamic game is

$$
\left\{\begin{array}{l}
p_{r}(t+1)=p_{r}(t)+\alpha_{1} p_{r}(t) \frac{\partial \pi_{r}(t)}{\partial p_{r}(t)} \\
p_{m}(t+1)=p_{m}(t)+\alpha_{2} p_{m}(t) \frac{\partial \pi_{m}(t)}{\partial p_{m}(t)} \\
w(t+1)=w(t)+\alpha_{3} w(t) \frac{\partial \pi_{m}(t)}{\partial w(t)} \\
e(t+1)=e(t)+\alpha_{4} e(t) \frac{\partial \pi_{m}(t)}{\partial e(t)}
\end{array}\right.
$$

Solving the dynamic system (8), we can get 16 equilibrium points (see $\mathrm{C}$, Table 2 ), and the solution containing zero value is the boundary point, that is, in this case, the decision maker will not choose, because when there is a variable value of zero, it does not meet the actual situation. Finally, we give the non-zero equilibrium solution as

$E^{*}=\left(p_{r}^{*}, p_{m}^{*}, w^{*}, e^{*}\right)$

Proposition 2 The equilibrium $E^{*}$ is locally asymptotically stable.

Proof See A for the proof.

In the constructed repeated dynamic game system, adjusting the parameters will have an impact on the stability of the system, so the influence of the parameters on the stability of the system can be observed to have a further understanding of the system. In order to describe the influence of parameters on the stable 
region more clearly, we give the stable region graph in the three-dimensional space, as shown in Fig. 2, the system parameters are fixed as: $a=4, c=0.5, b=0.3, \gamma=0.3, \theta=0.7, \rho=$ $0.9, \alpha_{4}=0.5$.

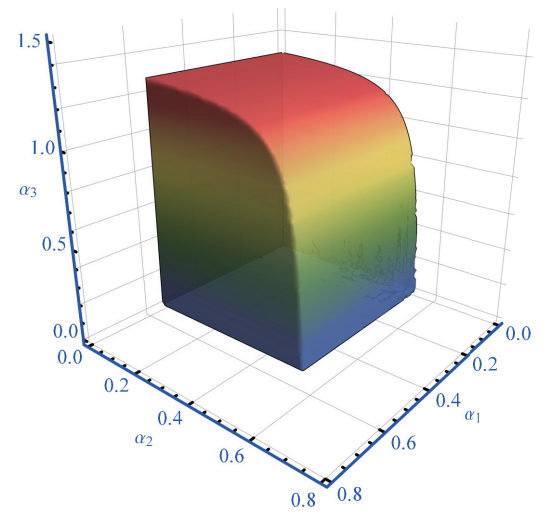

Fig. 2 System (8) stable region in $\left(\alpha_{1}, \alpha_{2}, \alpha_{3}\right)$ space.

Fig. 3 further shows the influence of market share on the stability region. It can be found that when theta changes, the stability region of the system will also change.

Fig. 3(a) shows the stable region when $\theta=$ $0.1,0.5,0.9$, and Fig. $3(\mathrm{~b})$ shows the stable region when $\theta=0.7,0.8,0.9$.

As the adjustment speed $\alpha_{1}$ or $\alpha_{2}$ changes, the dynamic system (8) show its evolution. In the following, we present the local bifurcation by varing the parameter. The bifurcation diagram as show in Fig. 4.

As show in Fig. 4, the price of retailer present a bifurcation diagrams with respect to the adjustment speed $\alpha_{1}$, and the price of direct channel, wholesale price, and carbon emission reduction level appear as three straight lines, which means that they will not change as the adjusted parameters $\alpha_{1}$ change. The three dashed lines indicate the bifurcation points of the period2 , the period- 4 and the period- 8 respectively.

Correspondingly, the bifurcation display in the two-dimensional plane and three-dimensional space is given in Fig. 5, where different colors indicate different numbers of cycles. Fig. 5(a) is the two-dimensional of bifurcation diagrams

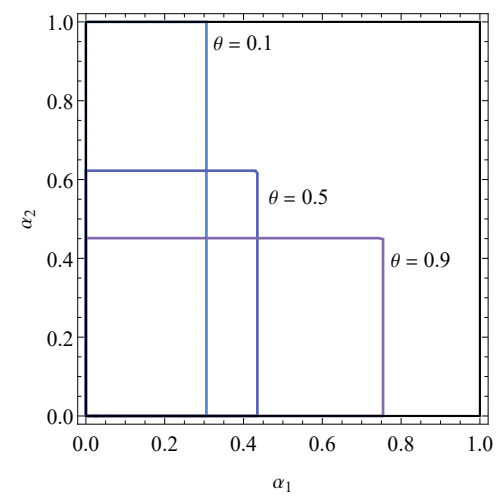

(a) Stability region via the adjustment speeds $\left(\alpha_{1}, \alpha_{2}\right)$ for different $\theta$.

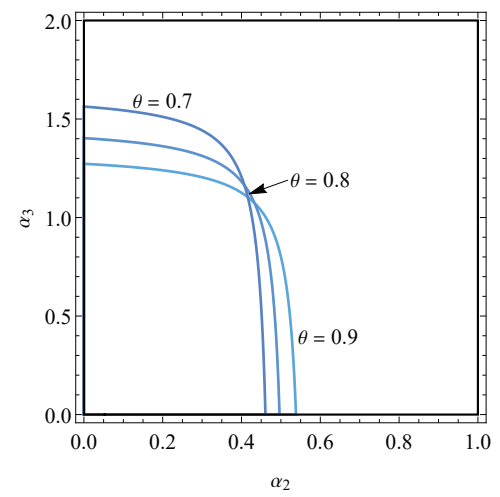

(b) Stability region via the adjustment speeds $\left(\alpha_{2}, \alpha_{3}\right)$ for different $\theta$.

Fig. 3 Stability region via the adjustment speeds $\left(\alpha_{1}, \alpha_{2}\right)$ and $\left(\alpha_{2}, \alpha_{3}\right)$ for different $\theta$.

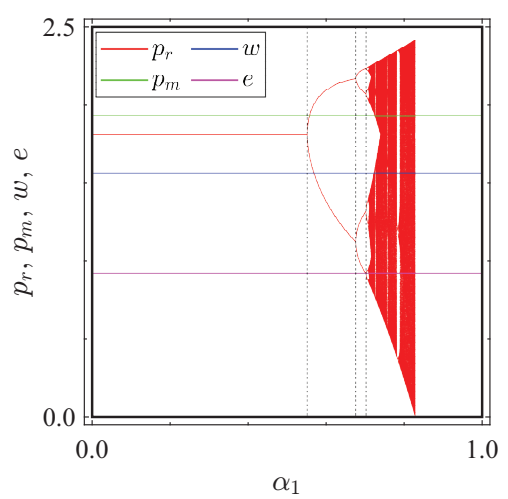

Fig. 4 Bifurcation diagrams of $p_{r}$ with respect to $\alpha_{1}$.

on $\left(\alpha_{2}, \alpha_{3}\right)$-plane, and Fig. $5(\mathrm{~b})$ is the three- 


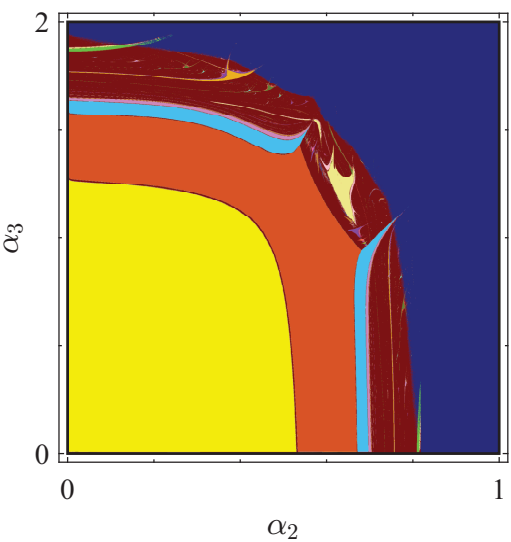

(a)

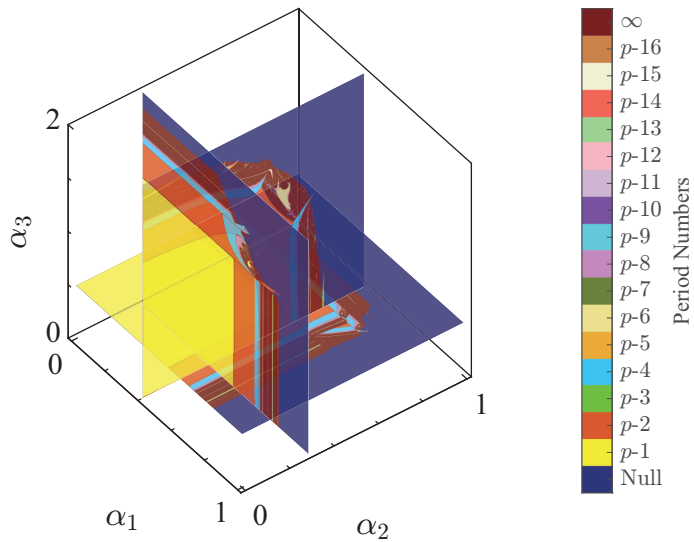

(b)

Fig. 5 Bifurcation diagrams of system (8) with respect to $\alpha_{1}, \alpha_{2}, \alpha_{3}$.

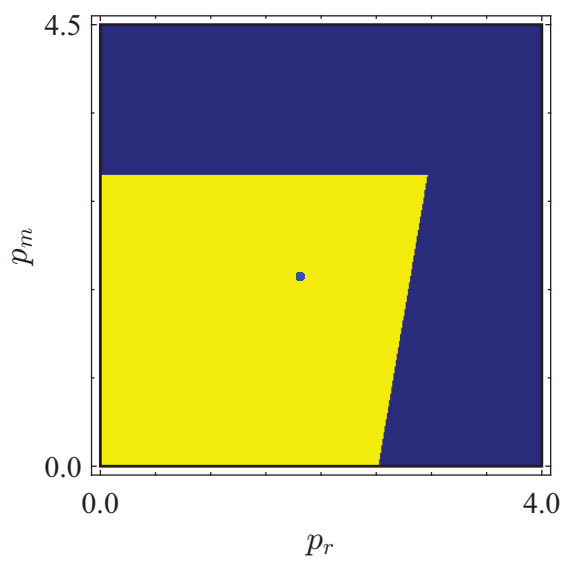

(a) Basin of attraction of period-1 in $\left(p_{r}, p_{m}\right)$-plane, $\alpha_{1}=\alpha_{2}=\alpha_{3}=\alpha_{4}=$ 0.5 .

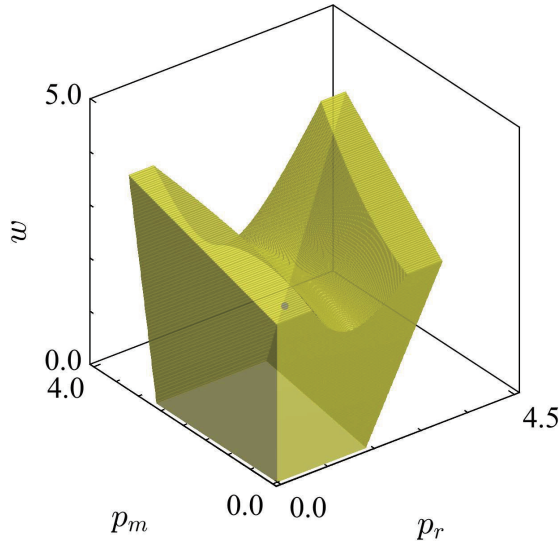

(c) Basin of attraction of period-1 in $\left(p_{r}, p_{m}, w\right)$-space, $\alpha_{1}=\alpha_{2}=\alpha_{3}=$ $\alpha_{4}=0.5$.

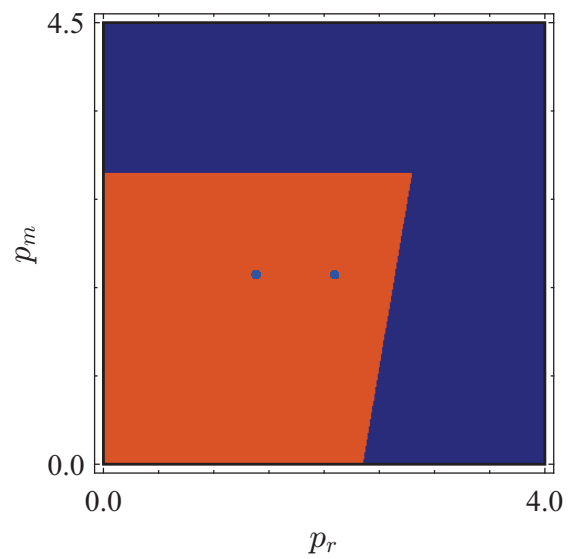

(b) Basin of attraction of period-2 in $\left(p_{r}, p_{m}\right)$-plane, $\alpha_{1}=0.6, \alpha_{2}=\alpha_{3}=$ $\alpha_{4}=0.5$.

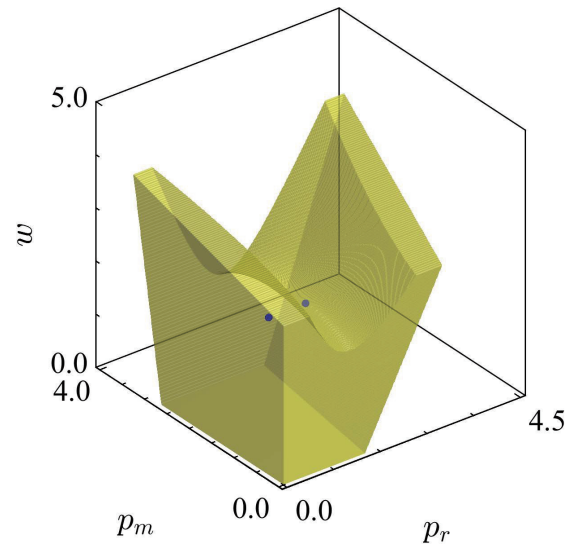

(d) Basin of attraction of period-2 in $\left(p_{r}, p_{m}, w\right)$-space, $\alpha_{1}=0.6, \alpha_{2}=\alpha_{3}=$ $\alpha_{4}=0.5$.

Fig. 6 Basin of attraction of system (8). 
dimensianl bifurcation diagrams in $\left(\alpha_{1}, \alpha_{2}, \alpha_{3}\right)$ space. Since the graph is complicated, three cross-sections are intercepted for representation. The three sections correspond to $\alpha_{1}=$ $0.4, \alpha_{2}=0.3, \alpha_{3}=0.5$.

In the previous sections, we analyzed and described the local bifurcation phenomenon, but from a global perspective, the selection of the initial value has an important impact on the evolution of the system, that is, the initial value may be outside the domain of the equilibrium point. In order to better analyze and compare the attraction domain, Fig. 6 shows the basin of attraction in the three-dimensional space.

As shown in Fig. 6, the yellow region in Fig. 6(c) is a period-1 stable basin of attraction, and the red point is a period-1 attractor. The yellow region in Fig. 6(d) is the period-2 basin of attraction, and the two blue points are the atrractor. Through comparison, it can be found that the shape of the period- 1 basin of attraction is different from that of the period-2 basin of attraction, which also indicates that as the parameters change, more and more complex scenarios will appear. Through the study of the basin of attraction, it can better guide the decision makers to select the initial value to ensure the final convergence in a stable domain.

Through the static and dynamic analysis of the decentralized decision making game model, we can find that there are complex dynamic characteristics. When considering different game models, decision makers tend to be more inclined to compare the benefits. Therefore, we next By comparing the expected benefits in the two models, we can better provide decisionmakers with decision making suggestions.

It can be found in Fig. 7 that there is a certain relationship between the average profit of static and dynamic games. When the $\alpha_{1}$ is small, the average profit of dynamic games is equal to the static games, but when alpha increases to a certain threshold, it will increase, and then it is lower than the profit in the static game model.

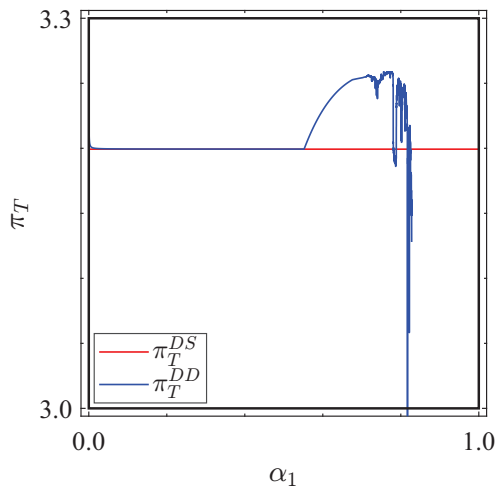

Fig. 7 The profit comparison between static model and dynamic model of decentralized decision.

\section{Centralized model}

Since the decentralized model seeks to maximize their respective profits, this may not be conducive to the overall development of the industrial chain. In order to further enhance the effectiveness of the research supply chain, we integrate manufacturers and retailers, and then conduct research on the integrated supply chain.

In the centralized model, the total profit is,

$$
\begin{aligned}
\pi_{T}= & \pi_{m}+\pi_{r} \\
= & p_{m}\left(\theta a-p_{m}+b p_{r}+\gamma e\right)+ \\
& \left(p_{r}-c\right)\left((1-\theta) a-p_{r}+b p_{m}+\gamma e\right)-\frac{1}{2} \rho e^{2}
\end{aligned}
$$

Through the Eq. (9), the optimal direct selling price $p_{m}$, the optimal retail price $p_{r}$ and the optimal emission reduction level $e$ can be obtained.

$$
\begin{aligned}
p_{r}^{*} & =\frac{(1+b) c\left(3 \gamma^{2}+2(-1+b) \rho\right)+a\left(\gamma^{2}(1-2 \theta)-2(1+(-1+b) \theta) \rho\right)}{4(1+b)\left(\gamma^{2}+(-1+b) \rho\right)} \\
p_{m}^{*} & =\frac{(1+b) c \gamma^{2}+a\left(\gamma^{2}(-1+2 \theta)+2 b(-1+\theta) \rho-2 \theta \rho\right)}{4(1+b)\left(\gamma^{2}+(-1+b) \rho\right)} \\
e^{*} & =-\frac{(a+(-1+b) c) \gamma}{2\left(\gamma^{2}+(-1+b) \rho\right)}
\end{aligned}
$$

Proposition 3 When $\rho>-\frac{\gamma^{2}}{-1+b}$, we can $o b$ tain the optimal decisions in the centralized model. 
Proof If we can obtain the optimal decisions, the Hessian matrix $H=\left(\begin{array}{ccc}-2 & 2 b & \gamma \\ 2 b & -2 & \gamma \\ \gamma & \gamma & -\rho\end{array}\right)$ should be negative definite. Due to $0<b<1,0<$ $\gamma<1,\left|\begin{array}{cc}-2 & 2 b \\ 2 b & -2\end{array}\right|=4\left(1-b^{2}\right)>0$. Therefore, let $\operatorname{det}(H)=4(1+b)\left(\gamma^{2}+(-1+b) \rho\right)<0$, then we can derived that $\rho>\frac{\gamma^{2}}{1-b}$.

\subsection{Dynamic centralized model}

The optimal decisions of manufacturers and retailers can be obtained in the static centralized decision model. Similarly, studying dynamic centralized decision making models can also get rich dynamic attributes. Dynamic centralized decision model is,

$$
\left\{\begin{array}{l}
p_{r}(t+1)=p_{r}(t)+\alpha_{1} p_{r}(t) \frac{\partial \pi_{T}(t)}{\partial p_{r}(t)} \\
p_{m}(t+1)=p_{m}(t)+\alpha_{2} p_{m}(t) \frac{\partial \pi_{T}(t)}{\partial p_{m}(t)} \\
e(t+1)=e(t)+\alpha_{3} e(t) \frac{\partial \pi_{T}(t)}{\partial e(t)}
\end{array}\right.
$$

There are 8 equilibrium solutions (see C, Table 3) in system (11). Among them, the boundary solution has zero value, so the decision maker is not within the scope of research. Among them, the non-zero solution is

$E^{*}=\left(p_{r}^{*}, p_{m}^{*}, e^{*}\right)$

Proposition 4 The equilibrium $E^{*}$ is locally asymptotically stable.

Proof See B for the proof.

Since the system (11) happens to consist of three expressions, it is possible to analyze the local bifurcation and global bifurcation properties of the system through the stability region in the three-dimensional space. The stable region in $\left(\alpha_{1}, \alpha_{2}, \alpha_{3}\right)$ space is shown in Fig. 8, the system parameters are fixed as: $a=4, c=$ $0.5, b=0.3, \gamma=0.3, \theta=0.7, \rho=0.9$.

Fig. 9 further shows the influence of market share on the stability region. It can be found that when theta changes, the stability region of the system will also change. Fig. 9(a) shows

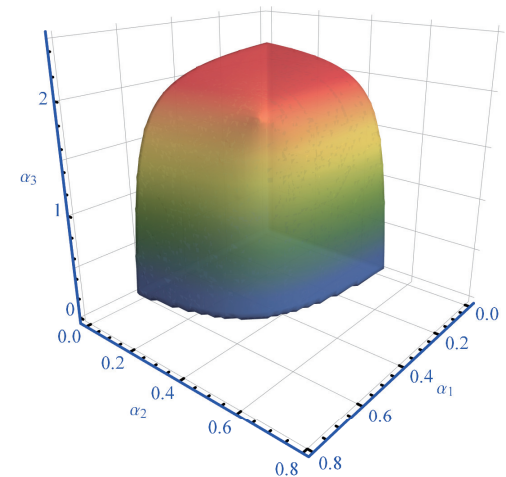

Fig. 8 System (11) stable region in $\left(\alpha_{1}, \alpha_{2}, \alpha_{3}\right)$ space.

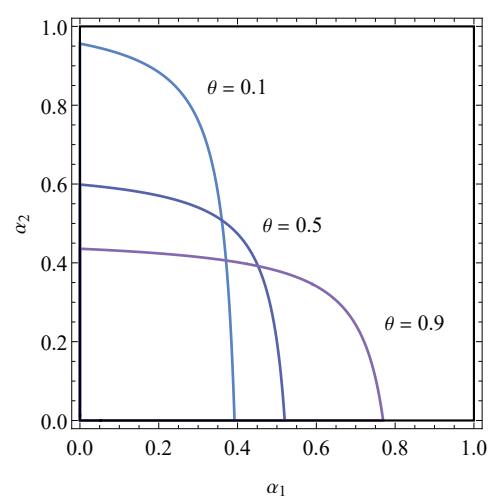

(a) Stability region via the adjustment speeds $\left(\alpha_{1}, \alpha_{2}\right)$ for different $\theta$.

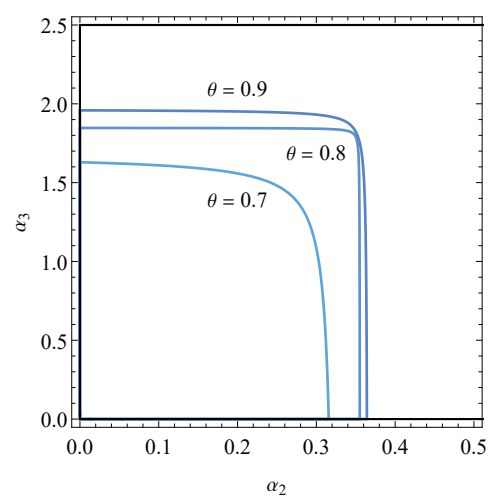

(b) Stability region via the adjustment speeds $\left(\alpha_{2}, \alpha_{3}\right)$ for different $\theta$.

Fig. 9 Stability region via the adjustment speeds $\left(\alpha_{1}, \alpha_{2}\right)$ and $\left(\alpha_{2}, \alpha_{3}\right)$ for different $\theta$.

the stable region when $\theta=0.1,0.5,0.9$, and 
Fig. 9(b) shows the stable region when $\theta=$ $0.7,0.8,0.9$.

Fig. 10 shows a local bifurcation diagram. When varying the adjustment speed $\alpha_{1}$, the system (11) will enter the period-doubling decision making state through flip bifurcation, and eventually lose stability and enter a chaotic state. The vertical dashed lines indicate that the system enters period-2, period- 4 and period8 respectively.

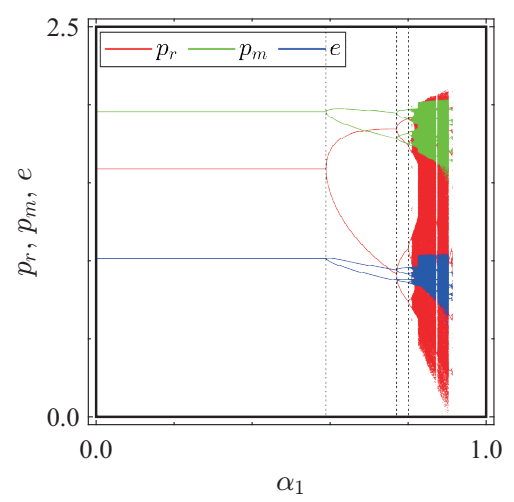

Fig. 10 Bifurcation diagrams of $p_{r}$ with respect to $\alpha_{1}$.

Correspondingly, the bifurcation diagram when the three variables change at the same time is given in Fig. 11. Fig. 11(a) is the twodimensional of bifurcation diagrams on $\left(\alpha_{1}, \alpha_{2}\right)$ plane. Since the changes in the three-dimensional space are very complicated, the cross-sections in three dimensions are shown in Fig. 11(b). Different colors correspond to different numbers of cycles. For example, blue is a divergent region, yellow is a stable period-1 region, and orange is a period- 2 region. The three sections correspond to $\alpha_{1}=0.4, \alpha_{2}=0.3, \alpha_{3}=0.5$.

We also performed global bifurcation analysis on the dynamic system (11) of the centralized decision model, and studied the initial value problems in two-dimensional space and three-dimensional space. Among them, Fig. 12 shows the basin of attraction composed of the retail price and the direct sales price on the two-dimensional plane and the corresponding attractor projection on the plane, which is then

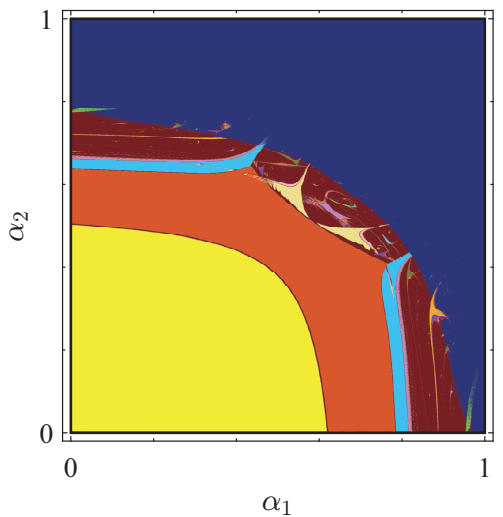

(a)

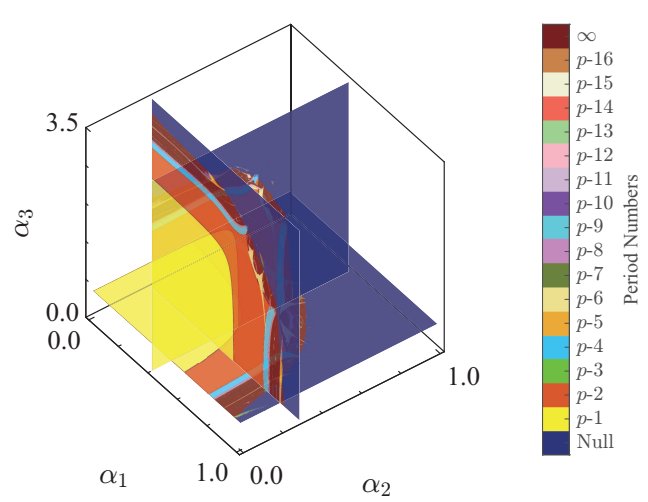

(b)

Fig. 11 Bifurcation diagrams of system (11) with respect to $\alpha_{1}, \alpha_{2}, \alpha_{3}$.

expanded into the three-dimensional space, giving basin of attraction in three-dimensional space of the retail price, direct selling price and carbon emission reduction level.

Studying the region of basin of attraction given by the dynamic system can ensure the effectiveness of the decision maker's initial strategy, that is, the initial strategy is within the convergent region. Fig. 12 shows the basin of attraction on the two-dimensional plane, $S=$ $\left\{\left(p_{r}, p_{m}\right) \in \mathcal{R}^{2}: p_{r}>0, p_{m}>0\right\}$, it is meaningful only when the initial value is within the region. The basin of attraction in the threedimensional space can be defined as $S=\left\{\left(p_{r}\right.\right.$, $\left.\left.p_{m}, e\right) \in \mathcal{R}^{3}: p_{r}>0, p_{m}>0, e>0\right\}$.

The dynamic system (11) is non-invertible, because its rank-1 preimage may not exist or 


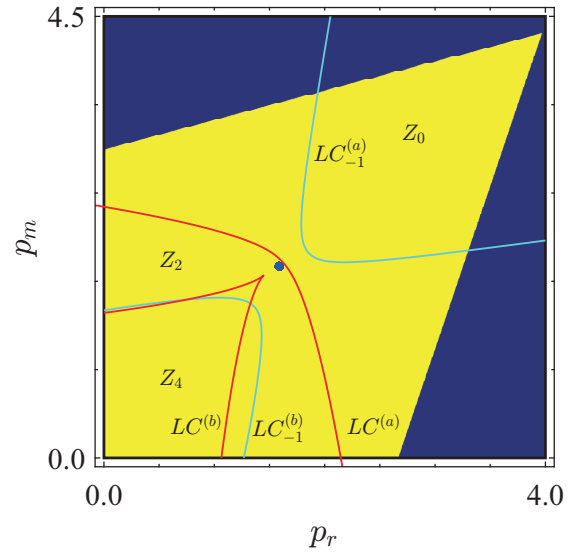

(a) Basin of attraction of period-1 in $\left(p_{r}, p_{m}\right)$-plane, $\alpha_{1}=\alpha_{2}=0.3$.

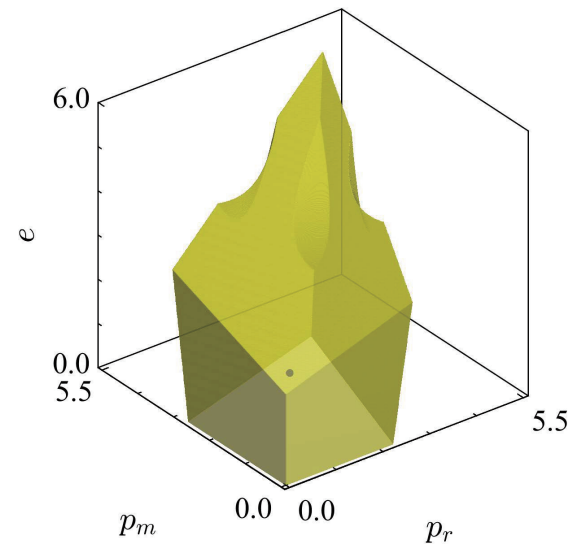

(c) Basin of attraction of period-1 in $\left(p_{r}, p_{m}, e\right)$-space, $\alpha_{1}=\alpha_{2}=0.3$.

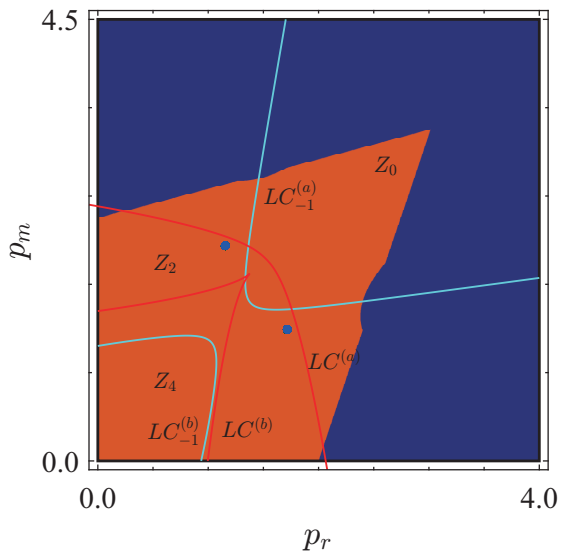

(b) Basin of attraction of period-2 in $\left(p_{r}, p_{m}\right)$-plane, $\alpha_{1}=\alpha_{2}=0.5$.

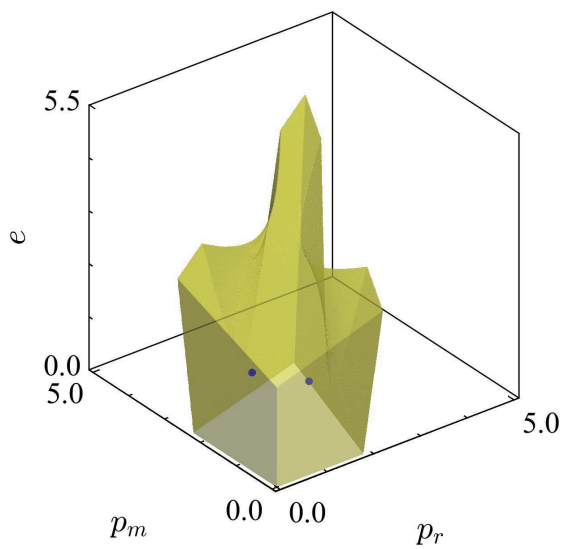

(d) Basin of attraction of period-2 in $\left(p_{r}, p_{m}, e\right)$-space, $\alpha_{1}=\alpha_{2}=0.5$.

Fig. 12 Basin of attraction of period-1 and of period-2 in system (11).

be multi-valued. For the convenience of observation, we only analyze the mapping on the two-dimensional $\left(p_{r}, p_{m}\right)$-plane. The blue region in Fig. 12(a) and 12(a) are non-convergent region. Here we introduce the concept of critical curve, i.e., $L C_{-1} \subseteq\left(p_{r}, p_{m}, e\right): \operatorname{det}\left(J\left(p_{r}\right.\right.$, $\left.\left.p_{m}, e\right)\right)=0$ and $T\left(L C_{-1}\right)=L C$.

By dividing the plane by the critical curve, region with different numbers of preimages can be obtained. The cyan curve and the red curve in Fig. 12(a) and 12(b) divide the plane into several regions, where the $Z_{0}$ region is no preimage, the $Z_{2}$ region indicates that there are two preimages, and the $Z_{4}$ region indicates that there are four preimages.

The dynamic system has complex characteristics, especially when the parameters change, colorful shapes and attributes may appear. Next, we further discuss the basin of attraction and attractors of system (11). In order to facilitate observation, we show this in a three-dimensional section. Fig. 13 shows the three-period basin of attraction, the coexistence of attractors, and chaotic attractors.

Fig. 13(a) shows a stable six-period, where the attractor is a projection on the $\left(p_{r}, p_{m}\right)$ plane, and Fig. 13(b) shows an invariant curve, 


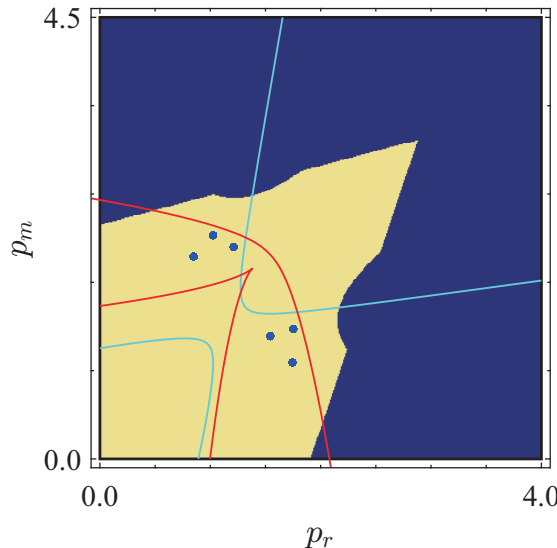

(a) $\alpha_{1}=\alpha_{2}=0.55$

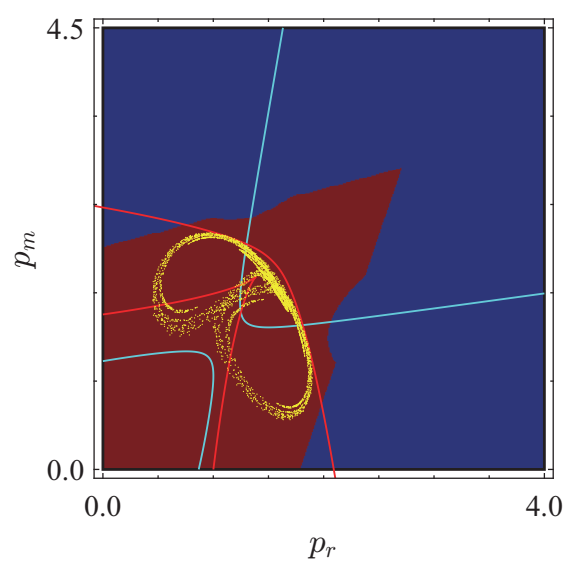

(c) $\alpha_{1}=\alpha_{2}=0.58$

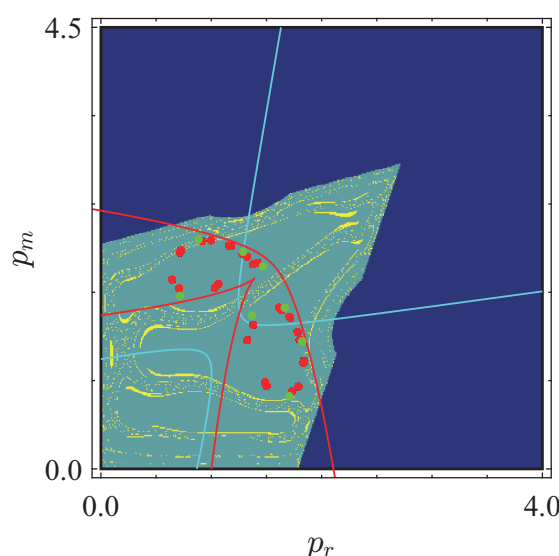

(e) $\alpha_{1}=0.56, \alpha_{2}=0.58$

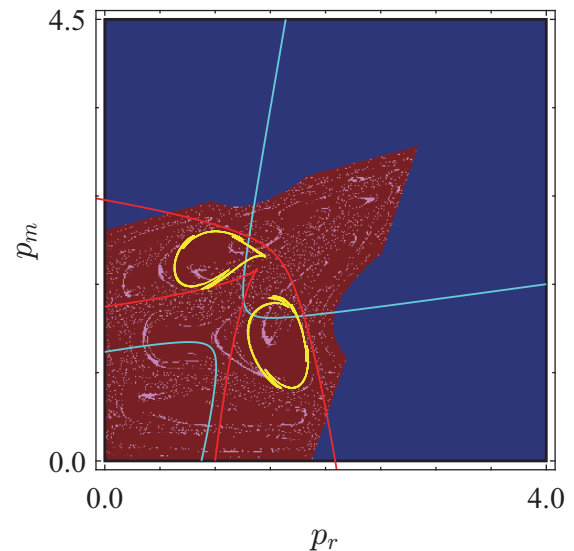

(b) $\alpha_{1}=\alpha_{2}=0.57$

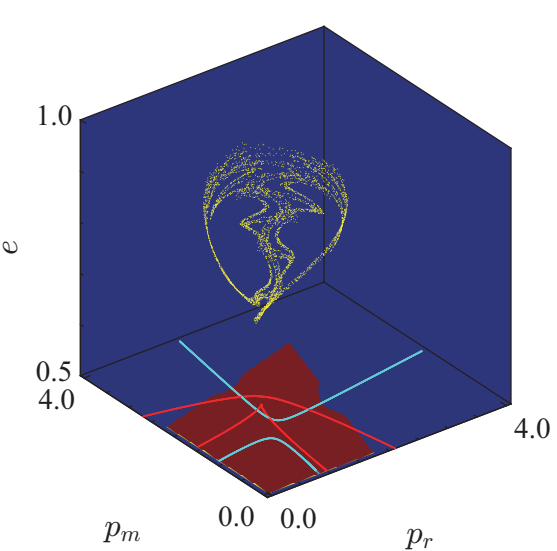

(d) $\alpha_{1}=\alpha_{2}=0.58$

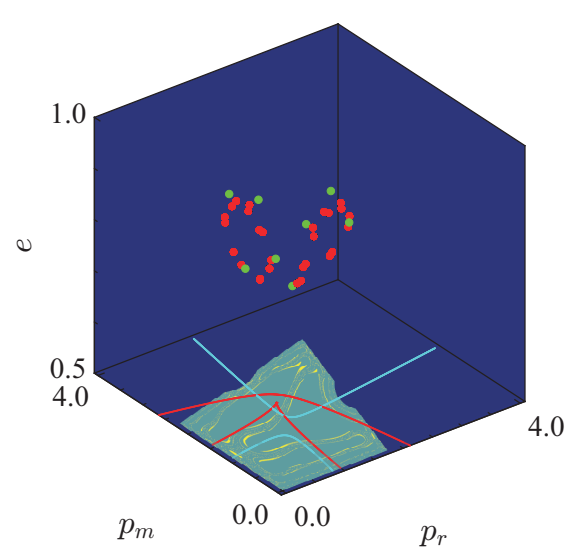

(f) $\alpha_{1}=0.56, \alpha_{2}=0.58$

Fig. 13 Basin of attraction with different parameter values. (a) The projection of the periods-6 on the $\left(p_{r}, p_{m}\right)$-plane. (b) The projection of the invariant curve on the $\left(p_{r}, p_{m}\right)$-plane. (c) The projection of the chaotic attractor on the $\left(p_{r}, p_{m}\right)$-plane. (d) The chaotic attractor in (c) and show in the $\left(p_{r}, p_{m}, e\right)$ space. (e) The projection of the coexistence periods- 8 and periods- 24 attractors on $\left(p_{r}, p_{m}\right)$-plane. (f) The coexistence attractors in (e) and show in the $\left(p_{r}, p_{m}, e\right)$-space. 
which is also a projection on the $\left(p_{r}, p_{m}\right)$ plane. Fig. 13(c) shows the chaotic attractor, Fig. 13(d) shows the attractor in three-dimensional space.

When the parameters appear in the critical bifurcation state, the phenomenon of attractors coexistence may appear. This coexistence phenomenon is shown in Fig. 13(e), where the green set attractor is an 8-period attractor, and its basin of attraction corresponds to the yellow area, and the red point set is a 24-period attractor, and its basin of attraction corresponds to the gray-green area. Fig. 13(f) shows the attractors in three-dimensional space.

In the game model of centralized decision making, in order to maximize the benefits of the overall supply chain, manufacturers and retailers jointly decide on direct selling prices, retail prices, and carbon emission reduction levels. At this time, the relationship between dynamic and static games is shown in Fig. 14 . It shows that in the static game, the profit is always greater than the average profit of the dynamic game.

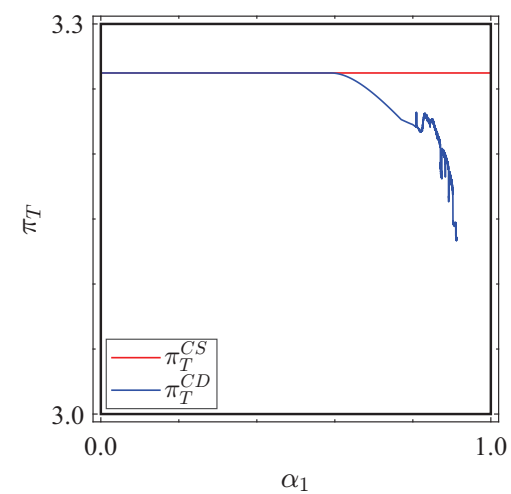

Fig. 14 The profit comparison between static model and dynamic model of decentralized decision.

\section{Profit comparison of dynamic centralized and decentralized models}

In the previous sections, we have studied and discussed the game models of different decision making sequences, and compared static games and dynamic games respectively. From this we can find that dynamic games are more complicated than static games. It becomes more difficult to compare the profits, here we take a numerical method to compare the average profit in different models.

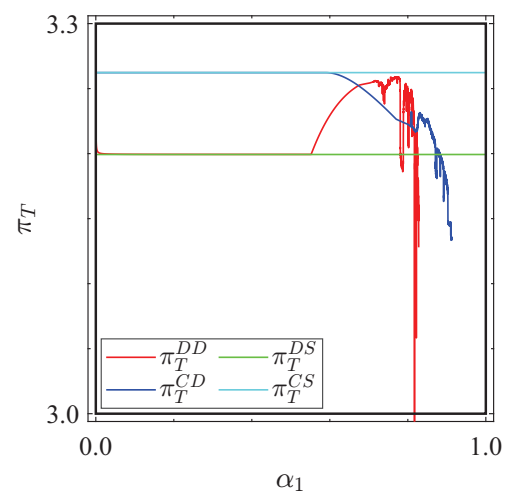

Fig. 15 The profit comparison between static model and dynamic model of decentralized decision.

Fig. 15 shows the profits of the four situations. It can be found that the profits in the static decentralized decision making (green) and static centralized decision making (cyan) models are a straight line independent of parameters, and the total profits of centralized decision making is higher than the decentralized decision making method. The dynamic game will present a complex curves, in which dynamic decentralized decision making (red) and dynamic centralized decision making (blue) will intersect, where when the parameter $\alpha_{1}$ gradually increases (that is, when entering bifurcation), the profits of dynamic centralized decision making will be decrease, and the profits of dynamic decentralized decision making will increase. Then there will be an intersection between the two, but when a certain value is reached, an irregular intersection will appear. This is the uncertainty that appears after entering the chaotic state. 


\section{Conclusion}

In this paper, consumers' preference for lowcarbon products is considered, and the optimal pricing strategy for manufacturers and retailers to introduce low-carbon products into production and sales in order to adapt to market demand is studied.

We separately studied the decentralized decision making and centralized decision making models, and combined with the long-term dynamic game method, respectively, we compared the static game and dynamic game results in different decision sequences. When the decision maker is in a static game (single cycle), since there are fewer parameters to consider and can collect as much information about opponents as possible, this can be regarded as a rational decision maker. However, when discussing dynamic games (multi-cycle), it is difficult for decision makers to predict all the information in the future. Therefore, it is necessary to consider the known decision results and conduct comprehensive considerations to arrive at a new optimal strategy when making decisions. This is why the long-term dynamic game is analyzed in the way of bounded rationality.

It can be found from the research result that dynamic games have more complicated conclusions than static games. When the parameters in a dynamic system change, the system may gradually lose its stability from a stable state and enter a chaotic state. This phenomenon is undesirable for decision makers, because the chaotic state of the system means that it is difficult to artificially predict future decisions, which is not conducive to decision makers to specify strategies.

In order to further study the complex characteristics of the dynamic system, this paper combines the local bifurcation and the global bifurcation theory to discuss the dynamic game system in detail. The law of the system changing with the parameters can be observed in combination with the bifurcation diagram. Decision makers provide more effective parameter ranges. Analyzing the basin of attraction of a dynamic system from a global perspective can avoid non-convergence. In addition, this paper also compares the benefits of different game models, so as to provide decision-makers with model selection suggestions under different information states.

In this paper, consumers' low-carbon consumption preferences are considered, and four game models are analyzed and compared. But in reality, there are more complicated situations that need to be studied further. In the future research work, we will consider the influence of more consumer preference factors on the model, as well as the complex phenomena in complex dynamics.

Acknowledgements We thank the senior editor, and two referees for their valuable suggestions, which have improved the study significantly.

\section{Funding}

The research was supported by The national natural science foundation of china (no:71571131).

\section{Conflict of interest}

The author(s) declare(s) that there is no conflict of interest regarding the publication of this paper.

\section{Data availability statement}

All data generated or analysed during this study are included in this published article [and its supplementary information files]. 


\section{A Proof of proposition 2}

Proof The dynamic system (8) is locally asymptotically stable at the equilibrium point $E^{*}$, when the characteristic polynomial of the corresponding Jacobian matrix $J$ satisfies the jury criterion.

$J=\left(\begin{array}{cccc}j_{11} & b p_{r} \alpha_{1} & p_{r} \alpha_{1} & p_{r} \alpha_{1} \gamma \\ 0 & j_{22} & b p_{m} \alpha_{2} & \frac{1}{2}(2+b) p_{m} \alpha_{2} \gamma \\ 0 & b w \alpha_{3} & j_{33} & \frac{w \alpha_{3} \gamma}{2} \\ 0 & \frac{1}{2}(2+b) e \alpha_{4} \gamma & \frac{e \alpha_{4} \gamma}{2} & j_{44}\end{array}\right)$

where where

$j_{11}=1+c \alpha 1+2 b p_{m} \alpha_{1}-4 p_{r} \alpha_{1}+e \alpha_{1} \gamma+a\left(\alpha_{1}-\alpha_{1} \theta\right)$
$j_{22}=1-4 p_{m} \alpha_{2}-b\left(c-2 p_{r}\right) \alpha_{2}+e \alpha_{2} \gamma+a \alpha_{2} \theta$
$j_{33}=1-c \alpha_{3} \gamma+p_{m} \alpha_{3} \gamma+p_{r} \alpha_{3} \gamma-2 e \alpha_{3} \rho$

The corresponding characteristic polynomial can be written as

$P(\lambda)=a_{3} \lambda^{3}+a_{2} \lambda^{2}+a_{1} \lambda+a_{0}$

According to the jury criterion, the following set of inequalities can be obtained.

$$
\begin{aligned}
& j_{11}=1+b p_{m} \alpha_{1}-4 p_{r} \alpha_{1}+w \alpha_{1}+e \alpha_{1} \gamma+a\left(\alpha_{1}-\alpha_{1} \theta\right)(A(1)>0 \\
& j_{22}=\frac{1}{2}\left(2-8 p_{m} \alpha_{2}+4 b^{2} p_{m} \alpha_{2}+2 e \alpha_{2} \gamma+\right. \\
& \left.b \alpha_{2}(-c+2 w+e \gamma)+a \alpha_{2}(b+2 \theta-b \theta)\right) \\
& j_{33}=\frac{1}{2}\left(2+c \alpha_{3}+2 b p_{m} \alpha_{3}-4 w \alpha_{3}+e \alpha_{3} \gamma+\right. \\
& \left\{\begin{array}{l}
(-1)^{n} A(-1)>0 \\
a_{n}>\left|a_{0}\right| \\
b_{n-1}>\left|b_{0}\right|
\end{array}\right.
\end{aligned}
$$$$
\left.a\left(\alpha_{3}-\alpha_{3} \theta\right)\right)
$$$$
j_{44}=\frac{1}{2}\left(2-c \alpha_{4} \gamma+(2+b) p_{m} \alpha_{4} \gamma+w \alpha_{4} \gamma-4 e \alpha_{4} \rho\right)
$$

The corresponding characteristic polynomial can be written as

$P(\lambda)=a_{4} \lambda^{4}+a_{3} \lambda^{3}+a_{2} \lambda^{2}+a_{1} \lambda+a_{0}$

According to the jury criterion, the following set of inequalities can be obtained.

$$
\left\{\begin{array}{l}
A(1)>0 \\
(-1)^{n} A(-1)>0 \\
a_{n}>\left|a_{0}\right| \\
b_{n-1}>\left|b_{0}\right| \\
c_{n-2}>\left|c_{0}\right|
\end{array}\right.
$$

where $b_{n-1}, b_{0}, c_{n-1}, c_{0}$ are obtained by Jury criterion. Since there are multiple parameters in the system (8), the result will be very complicated. Therefore, after multiple analyses, it can be concluded that there are situations that satisfy the above inequalities at the same time. The proof is complete. The proof is complete.

\section{B Proof of proposition 4}

Proof The dynamic system (1) is locally asymptotically stable at the equilibrium point $E^{*}$, when the characteristic polynomial of the corresponding Jacobian matrix $J$ satisfies the jury criterion.

$$
J=\left(\begin{array}{ccc}
j_{11} & 2 b p_{r} \alpha_{1} & p_{r} \alpha_{1} \gamma \\
2 b p_{m} \alpha_{2} & j_{22} & p_{m} \alpha_{2} \gamma \\
e \alpha_{3} \gamma & e \alpha_{3} \gamma & j_{33}
\end{array}\right)
$$

where $b_{n-1}, b_{0}$ are obtained by Jury criterion. Since there are multiple parameters in the system (11), the result will be very complicated. Therefore, after multiple analyses, it can be concluded that there are situations that satisfy the above inequalities at the same time. The proof is complete. 
C Solutions of dynamic system (8) and (11)

Table 2 All the solutions of dynamic system (8).

\begin{tabular}{|c|c|c|c|}
\hline$p_{r}$ & $p_{m}$ & $w$ & $e$ \\
\hline $\begin{array}{l}0 \\
0\end{array}$ & $\begin{array}{l}0 \\
0\end{array}$ & $\begin{array}{ll}0 \\
0 \\
0\end{array}$ & \\
\hline 0 & 0 & $\begin{array}{l}0 \\
\frac{1}{2}(a+c-a \theta)\end{array}$ & $0^{-\frac{-1}{2 \rho}}$ \\
\hline 0 & 0 & $\frac{2}{2} \gamma^{2}-2(a+c-a \theta) \rho$ & $\frac{\gamma(c+a(-1+\theta))}{?}$ \\
\hline 0 & $\frac{-a b+b c+a(-2+b) \theta}{2\left(-2+b^{2}\right)}$ & $0 \quad \gamma^{2}-4 \rho$ & $0^{\gamma^{2}-4 \rho}$ \\
\hline 0 & $\frac{a(b+\theta-b \theta)}{2-2 b^{2}}$ & $\frac{a+c-b^{2} c+a(-1+b) \theta}{2-2 b^{2}}$ & 0 \\
\hline 0 & $\frac{\gamma^{2}\left(-2 b^{2}\right.}{2(1+b+b c+2 a \theta)+4 a(b(-1+\theta)-\theta) \rho}$ & 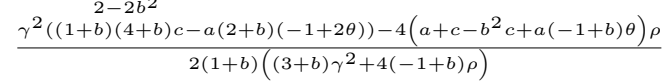 & $-\frac{\gamma((-1+b) c+a(1+b+\theta-b \theta))}{(3+b) \gamma^{2}+4(-1+b) \rho}$ \\
\hline 0 & $\frac{(2+b) c \gamma^{2}+2(-a b+b c+a(-2+b) \theta) \rho}{(2+b)^{2} \gamma^{2}+4\left(-2+b^{2}\right) \rho}$ & 0 & $\frac{\gamma((4-(-2+b) b) c+a(2+b)(b(-1+\theta)-2 \theta))}{(2+b)^{2} \gamma^{2}+4\left(-2+b^{2}\right) \rho}$ \\
\hline $\begin{array}{l}\frac{1}{4}(c-3 a(-1+\theta)) \\
\frac{1}{2}(a-a \theta)\end{array}$ & 0 & $\frac{1}{2}(a+c-a \theta)$ & o \\
\hline$\frac{\frac{T^{2}}{2}(a-a \theta)}{b^{2} c+a\left(-4+b^{2}+4 \theta-b(2+b) \theta\right)}$ & $\frac{-a b+b c+a(-2+b) \theta}{2\left(-2+b^{2}\right)}$ & 0 & 0 \\
\hline$\frac{1}{4}\left(c+\frac{a\left(-3+b^{2}-(-1+b)(3+b) \theta\right)}{-1+b^{2}}\right)$ & $\frac{a(b+\theta-b \theta)}{2-2 b^{2}}$ & $\frac{a+c-b^{2} c+a(-1+b) \theta}{2-2 b^{2}}$ & 0 \\
\hline$-\frac{c \gamma^{2}+2 a(-1+\theta) \rho}{4 \rho}$ & 0 & 0 & $-\frac{c \gamma}{2 \rho}$ \\
\hline$\frac{c\left(\gamma^{2}-\rho\right)+3 a(-1+\theta) \rho}{\gamma^{2}-4 \rho}$ & 0 & $\frac{c \gamma^{2}-2(a+c-a \theta) \rho}{\gamma^{2}-4 \rho}$ & $\frac{\gamma(c+a(-1+\theta))}{\gamma^{2}-4 \rho}$ \\
\hline$\frac{c\left(\gamma^{2}-\rho\right)+3 a(-1+\theta) \rho}{\gamma^{2}-4 \rho}$ & 0 & $\frac{c \gamma^{2}-2(a+c-a \theta) \rho}{\gamma^{2}-4 \rho}$ & $\frac{\gamma(c+a(-1+\theta))}{\gamma^{2}-4 \rho}$ \\
\hline$\frac{2(1+b) c \gamma^{2}-a(2+b) \gamma^{2}(-1+2 \theta)+b^{2} c \rho+a\left(-4+b^{2}+4 \theta-b(2+b) \theta\right) \rho}{(2+b)^{2} \gamma^{2}+4\left(-2+b^{2}\right) \rho}$ & $\frac{(2+b) c \gamma^{2}+2(-a b+b c+a(-2+b) \theta) \rho}{(2+b)^{2} \gamma^{2}+4\left(-2+b^{2}\right) \rho}$ & 0 & $\frac{\gamma((4-(-2+b) b) c+a(2+b)(b(-1+\theta)-2 \theta))}{(2+b)^{2} \gamma^{2}+4\left(-2+b^{2}\right) \rho}$ \\
\hline$\frac{-a(3+2 b) \gamma^{2}(-1+2 \theta)+2 a\left(-3+b^{2}-(-1+b)(3+b) \theta\right) \rho+(1+b) c\left(3 \gamma^{2}+2(-1+b) \rho\right)}{2(1+b)\left((3+b) \gamma^{2}+4(-1+b) \rho\right)}$ & $\frac{\gamma^{2}(-a+c+b c+2 a \theta)+4 a(b(-1+\theta)-\theta) \rho}{2(1+b)\left((3+b) \gamma^{2}+4(-1+b) \rho\right)}$ & $\frac{\gamma^{2}((1+b)(4+b) c-a(2+b)(-1+2 \theta))-4\left(a+c-b^{2} c+a(-1+b) \theta\right) \rho}{2(1+b)\left((3+b) \gamma^{2}+4(-1+b) \rho\right)}$ & $-\frac{\gamma((-1+b) c+a(1+b+\theta-b \theta))}{(3+b) \gamma^{2}+4(-1+b) \rho}$ \\
\hline
\end{tabular}


Table 3 All the solutions of dynamic system (11).

\begin{tabular}{lll}
\hline$p_{r}$ & $p_{m}$ & $e$ \\
\hline 0 & 0 & 0 \\
0 & 0 & $-\frac{c \gamma}{\rho}$ \\
0 & $\frac{1}{2}(-b c+a \theta)$ & 0 \\
0 & $\frac{c \gamma^{2}+b c \rho-a \theta \rho}{\gamma^{2}-2 \rho}$ & $\frac{\gamma((2+b) c-a \theta)}{\gamma^{2}-2 \rho}$ \\
$\frac{1}{2}(a+c-a \theta)$ & 0 & 0 \\
$\frac{a+c-b^{2} c+a(-1+b) \theta}{2-2 b^{2}}$ & $\frac{a(b+\theta-b \theta)}{2-2 b^{2}}$ & 0 \\
$\frac{c\left(\gamma^{2}-\rho\right)+a(-1+\theta) \rho}{\gamma^{2}-2 \rho}$ & 0 & $\frac{\gamma(c+a(-1+\theta))}{\gamma^{2}-2 \rho}$ \\
$\frac{\gamma^{2}(a+3(1+b) c-2 a \theta)-2\left(a+c-b^{2} c+a(-1+b) \theta\right) \rho}{4(1+b)\left(\gamma^{2}+(-1+b) \rho\right)}$ & $\frac{\gamma^{2}(-a+c+b c+2 a \theta)+2 a(b(-1+\theta)-\theta) \rho}{4(1+b)\left(\gamma^{2}+(-1+b) \rho\right)}-\frac{(a+(-1+b) c) \gamma}{2\left(\gamma^{2}+(-1+b) \rho\right)}$ \\
\hline
\end{tabular}




\section{References}

1. Adhikari, A., Bisi, A.: Collaboration, bargaining, and fairness concern for a green apparel supply chain: An emerging economy perspective. Transportation Research Part E: Logistics and Transportation Review 135, 101863 (2020). DOI 10.1016/j.tre.2020.101863

2. Agliari, A., Bischi, G.I., Dieci, R., Gardini, L.: Global bifurcations of closed invariant curves in two-dimensional maps: A computer assisted study. International Journal of Bifurcation and Chaos 15(04), 1285-1328 (2005). DOI $10.1142 / \mathrm{S} 0218127405012685$

3. Al-khedhairi, A., Matouk, A.E., Askar, S.S.: Bifurcations and chaos in a novel discrete economic system. Advances in Mechanical Engineering 11(4), 1687814019841818 (2019). DOI $10.1177 / 1687814019841818$

4. Askar, S.S.: Tripoly Stackelberg game model: One leader versus two followers. Applied Mathematics and Computation 328, 301-311 (2018). DOI 10.1016/j.amc.2018.01.041

5. Askar, S.S.: Duopolistic Stackelberg game: Investigation of complex dynamics and chaos control. Operational Research 20(3), 1685-1699 (2020). DOI 10.1007/s12351-018-0379-0

6. Bao, B., Ma, J., Goh, M.: Short- and longterm repeated game behaviours of two parallel supply chains based on government subsidy in the vehicle market. International Journal of Production Research 58(24), 7507-7530 (2020). DOI 10.1080/00207543.2020.1711988

7. Bao, B., Ma, J., Goh, M.: Short- and longterm repeated game behaviours of two parallel supply chains based on government subsidy in the vehicle market. International Journal of Production Research 58(24), 7507-7530 (2020). DOI 10.1080/00207543.2020.1711988

8. Bubicz, M.E., Dias Barbosa-Póvoa, A.P.F., Carvalho, A.: Social sustainability management in the apparel supply chains. Journal of Cleaner Production 280, 124214 (2021). DOI https://doi.org/10.1016/j.jclepro.2020.124214

9. Cai, Y.J., Choi, T.M.: A united nations' sustainable development goals perspective for sustainable textile and apparel supply chain management. Transportation Research Part E: Logistics and Transportation Review 141, 102010 (2020). DOI 10.1016/j.tre.2020.102010

10. Cai, Y.J., Choi, T.M., Zhang, T.: Commercial used apparel collection operations in retail supply chains. European Journal of Operational Research (2021). DOI https://doi.org/10.1016/j.ejor.2021.05.021

11. Cao, Y., Zhou, W., Chu, T., Chang, Y.: Global dynamics and synchronization in a duopoly game with bounded rationality and consumer surplus. International Journal of Bifurcation and Chaos 29(11), 1930031 (2019). DOI 10.1142/S0218127419300313

12. Chen, G., Ueta, T.: Yet another chaotic attractor. International Journal of Bifurcation and chaos 9(07), 1465-1466 (1999). DOI 10.1142/S0218127499001024

13. Dhir, A., Sadiq, M., Talwar, S., Sakashita, M., Kaur, P.: Why do retail consumers buy green apparel? a knowledge-attitudebehaviour-context perspective. Journal of Retailing and Consumer Services 59, 102398 (2021). DOI 10.1016/j.jretconser.2020.102398

14. Du, J., Huang, T., Sheng, Z.: Analysis of decision-making in economic chaos control. Nonlinear Analysis: Real World Applications 10(4), 2493-2501 (2009). DOI 10.1016/j.nonrwa.2008.05.007

15. Gardas, B.B., Raut, R.D., Narkhede, B.: Modelling the challenges to sustainability in the textile and apparel (t\&a) sector: A delphidematel approach. Sustainable Production and Consumption 15, 96-108 (2018). DOI 10.1016/j.spc.2018.05.001

16. Guo, S., Choi, T.M., Shen, B.: Green product development under competition: A study of the fashion apparel industry. European Journal of Operational Research 280(2), 523-538 (2020). DOI 10.1016/j.ejor.2019.07.050

17. Guo, Z.: Complexity and implications on channel conflict under the uncertain impacts of online customer reviews. Nonlinear Dynamics 96(3), 1971-1987 (2019)

18. Kumar, S., Yadav, R.: The impact of shopping motivation on sustainable consumption: A study in the context of green apparel. Journal of Cleaner Production p. 126239 (2021). DOI 10.1016/j.jclepro.2021.126239

19. Ma, J., Guo, Z., Hong, Y.: Complexity and implications on channel conflict under the uncertain impacts of online customer reviews. Nonlinear Dynamics 98(3), 1669-1681 (2019)

20. Ma, J., Li, T., Ren, W.: Research on the complexity of dual-channel supply chain model in competitive retailing service market. International Journal of Bifurcation and Chaos 27(07), 1750098 (2017). DOI 10.1142/S0218127417500985

21. Ma, J., Li, Y., Wang, Z.: Analysis of pricing and service effort in dual-channel supply chains with showrooming effect. International Journal of Bifurcation and Chaos 30(16), 2050241 (2020). DOI 10.1142/S0218127420502417

22. Ma, J., Lou, W., Tian, Y.: Bullwhip effect and complexity analysis in a multi-channel supply chain considering price game with discount sensitivity. International Journal of Production Research 57(17), 5432-5452 (2019). DOI 10.1080/00207543.2018.1526420

23. Ma, J., Xie, L.: The comparison and complex analysis on dual-channel supply chain under 
different channel power structures and uncertain demand. Nonlinear Dynamics 83(3), 13791393 (2016)

24. Ma, J., Xie, L.: The stability analysis of the dynamic pricing strategy for bundling goods: a comparison between simultaneous and sequential pricing mechanism. Nonlinear Dynamics 95(2), 1147-1164 (2018)

25. Mai, F., Zhang, J., Sun, X.: Dynamic analysis of pricing model in a book supply chain. International Journal of Production Economics 233, 108026 (2021). DOI https://doi.org/10.1016/j.ijpe.2021.108026

26. Moon, K.K.L., Youn, C., Chang, J.M., hon Yeung, A.W.: Product design scenarios for energy saving: A case study of fashion apparel. International Journal of Production Economics 146(2), 392-401 (2013). DOI 10.1016/j.ijpe.2013.02.024

27. Muthukumarana, T., Karunathilake, H., Punchihewa, H., Manthilake, M., Hewage, K.: Life cycle environmental impacts of the apparel industry in sri lanka: Analysis of the energy sources. Journal of Cleaner Production 172, 1346-1357 (2018). DOI 10.1016/j.jclepro.2017.10.261

28. Pal, K., Yasar, A.U.H.: Internet of things and Blockchain technology in apparel manufacturing supply chain data management. Procedia Computer Science 170, 450-457 (2020). DOI https://doi.org/10.1016/j.procs.2020.03.088.

The 11th International Conference on Ambient Systems, Networks and Technologies (ANT) / The 3rd International Conference on Emerging Data and Industry 4.0 (EDI40) / Affiliated Workshops

29. Pathirana, S., Yarime, M.: Introducing energy efficient technologies in small- and mediumsized enterprises in the apparel industry: A case study of sri lanka. Journal of Cleaner Production 178, 247-257 (2018). DOI 10.1016/j.jclepro.2017.12.274

30. Plotkina, D., Saurel, H.: Me or just like me? the role of virtual try-on and physical appearance in apparel m-retailing. Journal of Retailing and Consumer Services 51, 362-377 (2019). DOI 10.1016/j.jretconser.2019.07.002

31. Shepherd, H.: Thirsty for fashion? how organic cotton delivers in a water-stressed world. Tech. rep., Soil Association (2019)

32. Ueda, M.: Effect of information asymmetry in Cournot duopoly game with bounded rationality. Applied Mathematics and Computation 362, 124535 (2019). DOI 10.1016/j.amc.2019.06.049

33. United Nations Environment Programme: Putting the brakes on fast fashion. Tech. rep., United Nations Environment Programme (2018)
34. Wang, W., Zhou, W., Xia, L.: Dynamic evolution, synchronization and multistability in an advertising game model with homogeneous products and spillover effect. International Journal of Bifurcation and Chaos 30(10), 2050144 (2020). DOI $10.1142 / S 0218127420501448$

35. Xiao, Y., Peng, Y., Lu, Q., Wu, X.: Chaotic dynamics in nonlinear duopoly Stackelberg game with heterogeneous players. Physica A: Statistical Mechanics and its Applications 492, 1980-1987 (2018). DOI 10.1016/j.physa.2017.11.112

36. Yang, X., Peng, Y., Xiao, Y., Wu, X.: Nonlinear dynamics of a duopoly Stackelberg game with marginal costs. Chaos, Solitons \& Fractals 123, 185-191 (2019). DOI 10.1016/j.chaos.2019.04.007

37. Zhang, S., Wang, C., Yu, C., Ren, Y.: Governmental cap regulation and manufacturer's low carbon strategy in a supply chain with different power structures. Computers \& Industrial Engineering 134, 27-36 (2019). DOI 10.1016/j.cie.2019.05.026

38. Zhang, Y., Zhou, W., Chu, T., Chu, Y., Yu, J.: Complex dynamics analysis for a two-stage Cournot duopoly game of semi-collusion in production. Nonlinear Dynamics 91, 819-835 (2018). DOI 10.1007/s11071-017-3912-4

39. Zhou, J., Zhou, W., Chu, T., Chang, Y., Huang, M.: Bifurcation, intermittent chaos and multistability in a two-stage Cournot game with R\&D spillover and product differentiation. Applied Mathematics and Computation 341, 358378 (2019). DOI 10.1016/j.amc.2018.09.004

40. Zhu, W., He, Y.: Green product design in supply chains under competition. European Journal of Operational Research 258(1), 165-180 (2017). DOI https://doi.org/10.1016/j.ejor.2016.08.053 